That this objective was regarded as extremely important by the Association of British Chemical Manufacturers was made doubly clear by the unique offer made on behalf of the Instrument Advisory Committee by its chairman during his summing-up of the conference. This invited members of the conference to submit to the Advisory Committee an example of an actual working plant in order to obtain the Committee's recommendations on its instrumentation. The only condition attached to this offer was that, if the firm concerned implemented the recommendations, the results of it doing so should be published as an example of the technical and economic results which can follow the installation of improved instrumentation.

It will be very interesting to see the results of such a co-operative effort, which it must be anticipated will stimulate that appreciation of instrumentation by management which it was the object of the Conference to foster. Meanwhile, those who are responsible for factory management, and who were not able to be at the conference, should read the proceedings now published, with the view of applying some of the recommendations arising from the papers and discussions.

\section{DEVELOPMENTS IN OPTICS AND MICROWAVES}

T HE ever-increasing rate of scientific progress makes it difficult for research workers to keep abreast of developments within their immediate field of interest let alone those in related fields. With this consideration in mind, the Antennæ and Propagation Group of the Institute of Radio Engineers and the Optical Society of America held a joint symposium on microwaves and optics at the Lisner Auditorium of George Washington University during November 14-16. This was attended by some four hundred workers representing a wide range of interests in optics and microwaves and provided an excellent opportunity of comparing the present state of development in the two subjects. The first session was devoted to survey papers on microwaves ( $J$. Brown, University College, London), infra-red (J. A. Sanderson, Naval Research Laboratory, Washington), modern optical systems (A. Bouwers, N.V. Optische Industrie, Delft) and electron optics (L. L. Marton, National Bureau of Standards, Washington), and these served as a general background against which later more specialized papers could be appreciated.

Theoretical diffraction studies are of considerable importance to both microwave aerial and optical lens design, and an excellent account of current work was given by Prof. M. Kline and Dr. B. Keller, both of New York University. Both papers concentrated on the development of the theory in physical terms, Prof. Kline developing an asymptotic series solution beginning with the geometrical optics term, and Dr. Keller making extensive use of ray ideas. Such methods appeal to experimenters in that the significance of the various mathematical terms is evident physically. A historical account of the study of diffraction by a sphere (N. A. Logan, Air Force Cambridge Research Center) illustrated the wide. spread interest in using the work carried out in the late nineteenth and early twentieth centuries: a notable feature of the symposium as a whole was the awareness of how much the subject developed around the turn of the century.

Two papers on the optics of the eye, one by J. M. Enoch, of Ohio State University, on the nature of the receptors, and the other by H. A. Knoll, of the University of California, brought out many points of common interest. The receptors are similar in general form to microwave dielectric rod aerials, and scalemodel experiments carried out at centimetric wavelengths are providing useful information on the behaviour of these receptors. A complicating factor in the lens system of the eye is the variation of refractive index throughout its volume. Such nonhomogeneous lenses are now well established at microwave frequencies and their potentialities were described by K. S. Kelleher, of Melpar, Inc. There is a fruitful field here for further co-operation between those using optics and microwaves. The use of microwaves in interferometry, with possible applications to metrology, was discussed by W. Culshaw (National Bureau of Standards), and diffraction studies on microwave lens images were described by G. Bekefi and G. W. Farnell (McGill University). The relative ease with which both amplitude and phase can be measured at centimetric wave-lengths makes microwaves a powerful aid in further diffraction studies.

A full session was devoted to the implications of information theory to optical design. O. H. Schade (R.C.A.) described the elegant methods by which he has designed lens systems using communication theory, and A. Marechal (Institute of Optics, Paris) demonstrated the improvement in imaging which can result from optical filters operating on the amplitude and phase of the transmitted light. A general paper on the application of communication theory to optics by F. D. Smith (Boston University) led to a stimulating discussion: optical workers inclined to the view that communication theory would lead to no new significant results, one speaker remarking that the Fourier transform had been widely used before the introduction of information theory. On the other hand, it was evident that those whose interests lay in the communications field felt that the use of communication terminology and methods greatly facilitated their understanding of optical results.

F. T. Haddock (University of Michigan) surveyed the development of radio astronomy, and $W . H$. Bennet (Naval Research Laboratory) demonstrated the use of a new kind of valve which can be employed for studying the behaviour of proton streams under the action of magnetic fields. This was illustrated by an excellent film, and the results are being used to account for the properties of the aurora. The effects of the atmosphere on radio waves (M. Katzin, Electromagnetic Research Corporation) and on optics (W. E. Middleton, N.R.C., Canada) were shown to be similar in many respects. Duct propagation is an added complication in the microwave region; but apart from this the behaviour was seen to follow the same general trend in both cases.

The final session, to which F. J. Tischer (Ohio State University), K. Henize (Smithsonian Institution) and L. M. Hartman (G.E.C.) contributed, was devoted to problems arising in connexion with the observation of, and communication to, earth satellites and rockets. It appears that much information is still needed on the behaviour of electromagnetic waves through hypersonic shock layers associated with missile flights. 
A symposium of this kind is very valuable in that it directs attention to problems arising from a wide range of studies and in providing a meeting ground for people of very diverse interests. The Washington symposium was successful in both ways and is likely to lead to some interesting new work in the region common to optics and microwaves. J. BRown

\section{THE MEANING AND REACTIONS OF COMPLEMENT}

$\mathrm{B}^{\mathrm{Y}}$ $Y$ definition, complement is a hypothetical substance present in fresh serum that has the property of causing the escape of hæmoglobin from red blood cells that have combined with antibody. There are, however, also a number of other reactions for which complement or substances resembling complement are essential ; these other reactions were the chief subjects discussed in the symposium on "Complement" at the first meeting of the newly formed British Society for Immunology during November 9-10.

As Prof. J. R. Marrack pointed out in his introduction to that symposium, the first and second components of complement can be separated in mid. and end-piece, and the third component can be obtained free from other compononts; but the fourth component has not been prepared free from other components and may well be an active group of the first and/or second component.

Bordet ${ }^{1}$ wrote of 'fixation' of complement and the expression is established by long usage. But all that is observed when complement is 'fixed' by antigenantibody complexes is that complement activity is lost. It seems that the only evidence that the active substance actually combines is found in exporiments that Dean ${ }^{2}$ published in 1912. He found that an antigen-antibody precipitate, formed in the presence of mid-piece in the cold, washed and resuspended, had mid-piece activity. Otherwise the only evidence that any component of complement is fixed are the facts, first shown by Heidelberger ${ }^{3}$ in 1941 , that a complement-fixing antigen-antibody system forms more precipitate in the presence of fresh serum than in inactivated serum; and that this difference is not found when the antigen-antibody system is one, such as pneumococcal polysaccharide and horse antiserum, that does not fix complement. Mr. R. G. S. Johns presented a diagram showing this increase in precipitate over a wide range of ratios of antigon (ovalbumin) to antibody in the presence of fresh human serum; in the presence of heat-inactivated serum the amounts of precipitate were almost identical with those of the saline controls. With horse serum as the source of complement the matter was less simple; for over a wide range of antigen/ antibody ratios the amount of precipitate formed in the presence of heat-inactivated horse serum was less than that formed in saline. This recalls the demonstration by Maurer and Talmage, using antigen and antibody labelled with iodine-131, that the amounts of antigen and antibody precipitated differed in the absence or presence of complement.

Heidelberger has shown that most of the protein taken up from fresh serum by an antigen-antibody precipitate comes from the fraction containing the first component. Mr. Johns could find no evidence that the second and fourth components added anything to the precipitate; they may therefore be inactivated and not actually fixed. The extra protein derived from fresh serum is not merely entrapped when the antigen-antibody precipitate is formed, for Mr. Johns found that a pre-formed precipitate, resuspended with fresh serum, will eventually take up as much protein as would have been added if the precipitate had boen formed in the presence of the fresh serum.

The work of Levine, Mayer and colleagues ${ }^{5}$ has demonstrated three stages in the interaction of complement with sensitized red-blood cells. In the first stage, which requires calcium ions, the first and fourth components are involved; in the second, which requires magnesium ions but not calcium ions, the socond component is involved; in the third stage, which is very slow at temperatures below $17^{\circ}$, the third component effects a change in the red cells, the result of which is the escape of hæmoglobin. The product $(a)$ of the first stage and that $(b)$ of the second stage are unstable; at $37^{\circ}$ they are in. activated - that is, they undergo such a change that the further stages no longer take place on addition of the appropriate components. The inactivation of $b$ is rapid, so that the eventual degree of lysis depends on a race between this inactivation and the action of the third componont. Furthermore, Levine ${ }^{6}$ has found that after treatment of $a$ with isopropylfluorophosphate, which is regarded as a specific inhibitor of esterases, hæmolysis does not occur on addition of second and third components. Treatment of serum that contains complement-that is, treatment of complement that has not been fixed-does not inactivate the complement. Also, Becker ${ }^{2}$ finds that product $b$ (or its inactivated form) hydrolyses tosylarginine methyl ester, whereas neither the serum from which the complement is derived nor red blood cells without complement hydrolyse this substrate. We have, therefore, a method of demonstrating a change in complement after 'fixation', apart from the hæmolysis of red blood cells. It would be interesting to know whether an esterase is either formed or becomes activated when complement is fixed by simple antigen-antibody precipitates.

We have further evidence of a change in complement on fixation in the conglutinin reaction. Bordet and Streng8 found that bovine serum agglutinated sensitized red blood-cells and other antigen-antibody complexes that had fixed complement (particularly horse complement); they called this reaction conglutination and postulated a substance, conglutinin, in the bovine serum. Unfortunately, much confusion has been caused by the application of the name 'conglutination' to other reactions in which complement is not involved; but at this symposium the word was used in the correct sense. Streng and Wartiovara ${ }^{10}$ have shown that though normal rabbit serum contains little conglutinin, something very similar to it appears in the serum of rabbits after intravenous injection of antigen-antibody complexes that have fixed complement; this conglutinin-like substance, which appears to be an antibody against fixed complement, they called immunoconglutinin; it is permissible to suppose that the natural conglutinin is also an antibody against fixed complement. Wartiovara ${ }^{10}$ and Coombs and Coombs ${ }^{11}$ found that this conglutinin-like substance was also formed after bacteria alone, without antibody, were injected, and considered that this immunoconglutinin was antibody against the rabbit's own complement fixed on 